\title{
Effectiveness of 1:1 speech and language therapy for older children with (developmental) language disorder
}

\author{
Susan H. Ebbels ${ }^{1,2}$, Lisa Wright ${ }^{1}$, Sally Brockbank ${ }^{1}$, Caroline Godfrey ${ }^{1}$, \\ Catherine Harris ${ }^{1}$, Hannah Leniston ${ }^{1}$, Kate Neary ${ }^{1}$, Hilary Nicoll ${ }^{1}$, Lucy Nicoll ${ }^{1}$, \\ Jackie $\operatorname{Scott}^{1}$, Nataša Marićc ${ }^{1}$ \\ ${ }^{1}$ Moor House School \& College, Surrey, UK \\ ${ }^{2}$ Division of Psychology and Language Sciences, University College London, UK
}

Sally Brockbank is now at The PACE Centre, Aylesbury

Caroline Godfrey is now at London Borough of Merton

Kate Neary is now at Ingfield Manor School, West Sussex

Lisa Wright is now at Meath School, Surrey

Correspondence concerning this article should be addressed to Susan Ebbels, Moor House School \& College, Mill Lane, Hurst Green, Oxted, Surrey, RH8 9AQ, UK. ebbelss@moorhouseschool.co.uk.

Keywords: intervention, developmental language impairment, receptive language, adolescents, evidence-based practice (EBP), specific language impairment (SLI) 


\section{Abstract \\ Background:}

Evidence of the effectiveness of therapy for older children with Developmental Language Disorder (DLD) and particularly those with receptive language impairments is very limited. The few existing studies have focused on particular target areas, but none has looked at a whole area of a service.

Aims: We aimed to establish whether for students with severe DLD attending a specialist school, 1:1 intervention with an SLT during one school term improves performance on targeted areas, compared with un-treated control areas. We also investigated whether gender, receptive language status, ASD status, or educational Key Stage affected their response to this intervention.

\section{Methods \& Procedures:}

72 students (aged 9-17 years, 88\% of whom had receptive language impairments) and all SLTs in our specialist school for children with DLD participated in this study over one school term. During this term, the SLTs devised pre- and post-therapy measures for every student for each target they planned to treat 1:1. In addition, for each target area, a control measure was devised. The targets covered a wide range of speech, language and communication areas, both receptive and expressive. Post-therapy tests were administered 'blind'.

\section{Outcomes \& Results:}

During the term, SLTs and students worked 1:1 on 120 targets, the majority in the areas of expressive and receptive language. Targets and controls did not differ pre-therapy. Significant progress was seen both on targets $(d=1.33)$ and controls $(d=0.36)$, but the targeted areas improved significantly more than the controls with a large and clinically significant 
effect size $(d=1.06)$. There was no effect of language area targeted (targets improved more than their controls for all areas).

Participants with versus those without receptive language difficulties, co-occurring ASD diagnosis or participants in different educational Key Stages did not differ significantly in terms of the progress they made on target areas.

\section{Conclusions \& Implications:}

Direct 1:1 intervention with an SLT can be effective for all areas of language for older children with DLD, regardless of their gender, receptive language or ASD status, or age. This adds to the relatively limited evidence base regarding the effectiveness of direct SLT intervention for school-aged children with DLD and for children with receptive language impairments. If direct 1:1 intervention can be effective with this hard-to-treat group, it may well also be effective with younger children with DLD. Thus, direct SLT services should be available for school-aged children with DLD, including older children and adolescents with pervasive difficulties. 


\section{What this paper adds}

\section{What we already know}

Older children and adolescents with Developmental Language Disorder are often excluded from services and have only been included in a few intervention research studies. Progress is difficult to show using standardised tests, particularly where the children have receptive language impairments. However, when specific areas are targeted and outcomes in these areas are measured, significant progress can be demonstrated. Services for this group of children need to provide intervention for a wide range of areas of need; for many of these, there is no evidence base due to limited research with this group.

\section{What this paper adds to existing knowledge}

We showed that older children and adolescents, most of whom have receptive language impairments, can make progress in a wide range of areas with direct 1:1 therapy with an SLT. Their response to this individualised intervention is not affected by their receptive language status, a co-occurring diagnosis of ASD, or by educational Key Stage. The rate of progress on targets relative to their controls was similar for targets rated as "achieved" versus " not achieved”.

\section{What are the potential or actual clinical implications of this work}

Simple outcome measures of whether a target is "achieved" versus "not achieved" should be treated with caution when no control measure is available for comparison. Older children with DLD, including those with receptive language impairments or co-occurring ASD, can make good progress with 1:1 direct therapy with an SLT and thus should not be excluded from clinical services. Children and young people such as those in our study would 
often be regarded as hard-to-treat. Therefore, if direct 1:1 intervention can be effective with this group, it may well also be effective with younger children with DLD. 


\section{Introduction}

Approximately $7 \%$ of children have a Developmental Language Disorder (DLD) when they enter school (Tomblin et al., 1997) and for some, this persists into adolescence, affecting their educational achievements (Conti-Ramsden, 2008) and into adulthood, affecting their employment prospects (e.g., Law et al., 2009). Children with both receptive and expressive language impairments are most likely to have persisting difficulties (Beitchman et al., 1996, Tomblin et al., 2003). Indeed, Clark et al. (2007) found that only two of fifty-eight children with severe receptive language impairments at school entry had language scores in the normal range six years later.

Despite the long-term difficulties of children with DLD, particularly those with both receptive and expressive language impairments, few intervention studies have been carried out including these children (see Ebbels, 2014 for a review). This is particularly the case for secondary school-aged children and adolescents, who also receive limited professional services (Dockrell et al., 2006) and have been included in only a handful of studies (Bishop et al., 2006, Bragard et al., 2012, Ebbels and van der Lely, 2001, Ebbels, 2007, Ebbels et al., 2014, 2012, 2007, Hyde-Wright et al., 1993). However, it could be argued that children with such persisting difficulties are most in need of intervention as their difficulties are very unlikely to resolve spontaneously. The participants in these studies all had receptive language impairments, which is perhaps unsurprising given the link between persistence of difficulties and the presence of receptive language impairments. However, studies including secondaryaged children with persisting DLD where receptive language is relatively intact are severely lacking.

Of the few studies that have investigated intervention for older primary and secondary-aged children with DLD including those with receptive language difficulties, several have failed to find any significant effects of intervention (Bishop et al., 2006, Boyle et 
al., 2009, Gillam et al., 2008, McCartney et al., 2011), despite in some studies more than 20 hours of intervention being provided (19-25 hours in Boyle et al., 2009, 50 hours in Gillam et al., 2008) on a range of targets and language areas. However, in the Boyle et al. (2009) study, unlike the children with receptive language impairments, children with expressive language difficulties but good receptive language did make progress. Thus, it seems that children with receptive language impairments are not only more likely to have difficulties which persist into secondary school, but are also more difficult to treat. However, the above studies covered a range of targets and language areas and only used global standardised tests, where it is difficult to show progress after a short period of intervention.

Other studies have used more specific measures of progress which are more closely related to the target of intervention. These studies have generally had more positive results with children with receptive language impairments and have found significant progress with therapy targeting receptive vocabulary (Parsons et al., 2005, Throneburg et al., 2000), word finding (Ebbels et al., 2012, Hyde-Wright et al., 1993), production and comprehension of specific grammatical structures (Ebbels and van der Lely, 2001, Ebbels, 2007, Ebbels et al., 2014, 2007) and general text and sentence comprehension (Joffe et al., 2007, Tallal et al., 1996). Several of these studies provided less than five hours of intervention (Ebbels et al., 2007, 2012, 2014, Joffe et al., 2007), while others provided between five and ten hours of intervention (Ebbels, 2007, Ebbels et al., 2007, Parsons et al., 2005, Throneburg et al., 2000, Hyde-Wright et al., 1993). Thus, it seems that school-aged children with receptive language impairments can be shown to make progress with even relatively small amounts of intervention when that intervention is targeted to a specific area and the outcome measures are closely linked to the intervention. It should be noted, that the participants in all of these studies (with the exception of Throneburg et al., 2000) had DLD of sufficient severity that they were either receiving specialist education in specialist language school (studies by 
Ebbels and colleagues and Hyde-Wright et al. 1993) or receiving support from a Language Resource base (Parsons et al., 2005) or language unit (Joffe et al., 2007).

As a team of Speech and Language Therapists (SLTs) working in a specialist school for children aged 7-19 years with severe, persistent DLD, the majority of whom have receptive language impairments, the evidence of progress with specific language targets for this group is encouraging and we routinely use the methods from the above studies in our therapy sessions when targeting related areas. However, the range of therapy targets and methods provided in our usual practice is much wider than those in the published studies above, due to the mismatch between the wide range of needs and the limited evidence base. Targets and therapy methods are determined by individual SLTs, taking into consideration the specific needs of the student, the views of the students, their parents and teachers as well as the potential functional impact progress on any target may have on their life either at home or school. Because of the lack of an evidence base to inform much of our intervention, we wanted to know whether our SLT provision as routinely provided was effective. Due to the wide range of targets and methods and the fact that all students in the school were receiving therapy, the effectiveness of this therapy can be hard to evaluate. However, a study with younger children (Mecrow et al., 2010) provided a suitable study design.

Mecrow et al. (2010) considered the effectiveness of an "enhanced consultative model" with children (aged 4;2-6;10) attending mainstream primary schools in Key Stage 1 (from Reception to Year 2 in the UK, when children are aged 4-7 years). All children scored 1.5 SD below the mean on percentage of phonemes correct or receptive or expressive language on standardised tests. Thus, they had a range of profiles of speech and language abilities (22/35 had receptive language difficulties). Mecrow and colleagues investigated the effectiveness of 1:1 intervention provided by assistants. These assistants were employed to work under the guidance of SLTs or specialist language teachers and made available to 
schools to work with individual children. They compared progress on (individualised) targeted versus control areas. Progress on targets (a mixture of speech and language, receptive and expressive) was significantly greater than progress on control areas. However, they did not analyse whether the effectiveness of this model of therapy provision varied between target areas or between different groups of children.

We used the Mecrow et al. (2010) study as a model to evaluate the effectiveness of part of our therapy service (direct therapy provided 1:1 by an SLT). As we had a greater number of potential participants than the Mecrow et al. (2010) study, we also aimed to analyse any differences in response to intervention with respect to target area and participant characteristics. The majority of our students (but not all) have receptive language impairments. Given that the previous literature tends to show less convincing progress for children with receptive language impairments (Boyle et al., 2009, Law et al., 2003), we investigated whether having poor receptive language affected progress on targets selected for each individual student. A minority of our students have a diagnosis of ASD in addition to their language impairment. This could also affect response to intervention, so we also analysed whether the presence of ASD affected progress. The final characteristic we considered was gender. This is because while girls are in the minority in our school, they tend to have more severe language impairments and thus, they may respond differently to intervention.

In the school, each student has a "core SLT" for 1:1 therapy. Collaborative teaching, planned and delivered jointly by the teacher and SLT, is also a key feature (particularly in English, Science, $\mathrm{PSHCE}^{1}$, social and life skills lessons, but also in some other specialist subject lessons). In addition the students participate in group work with an SLT who may or may not be their core SLT. In Key stages 2 (years 3-6, aged 7-11 years) and 3 (years 7-9,

\footnotetext{
${ }^{1}$ PSHCE $=$ Personal, Social, Health and Citizenship Education
} 
aged 11-14 years), students receive at least two paired or individual sessions per week with their core SLT (many receive more; this depends on their needs as detailed in their statement of Special Educational Needs or Education, Health and Care Plan), at least one group SLT session and collaborative class teaching. In Key stage 4 (years 10-11, aged 14-16 years), students receive at least one paired or individual session with their core SLT per week, at least two group SLT sessions and collaborative class teaching. Due to the differences in provision during the different Key Stages, we also investigated whether progress differed by

educational Key Stage. In this study, in order to reduce the number of variables, we only evaluated the effectiveness of therapy provided 1:1 by each student's core SLT during one school term.

\section{Aims}

Our primary research question was: In students with severe DLD attending a specialist school, does 1:1 therapy with an SLT during one school term improve performance on targeted areas, compared with un-treated control areas and does this vary with area of language targeted?

Our two secondary research questions were: 1) In targets rated as "achieved" versus "not achieved", does progress on targets relative to their controls differ? 2) In students with severe DLD attending a specialist school, do gender, receptive language status, ASD status, or educational Key Stage affect response to targeted 1:1 intervention with an SLT?

\section{Method}

\section{Participants}

This study was carried out at a specialist day and residential school for students with DLD in the United Kingdom. At the start of the study 75 students attended the school and all had a statement of Special Educational Needs. The school currently caters for students aged 
$7-19$, but at the time of the study the post-16 college provision had only recently opened and students attending the college were not included in this study. The age of the students attending the school provision at the time ranged from 9-17 years; we had no students aged 78 at the time and one student had been held back a year and therefore was 17 , but still in the school provision.

Of these 75 students, during the term of the project, 72 received individual therapy on at least one target with an SLT (others received paired therapy with an SLT during that term). These 72 students are the participants in this study. Some participants also received 1:1 therapy with an SLT assistant, but the numbers were too small to include. All SLTs in the school were involved.

Of the 72 participants, $63(88 \%)$ had receptive language impairments $(<85$ on receptive language index of CELF-4 (Semel et al., 2006)), 20 (28\%) had a diagnosis of ASD and $20(28 \%)$ were girls. Seven participants (10\%) were in Key Stage 2 (years 3-6, aged 711), 39 (54\%) were in Key Stage 3 (years, 7-9, aged 11-14) and 26 (36\%) were in Key Stage 4 (years 10-11, aged 14-16). Table 1 gives a summary of the participants' ages and performance on standardised tests. Most of those with one or more scores in the normal range on these tests had language difficulties which were more pragmatic in nature (indeed some had a diagnosis of ASD).

Table 1: Mean and standard deviations (SD) of participants' age and standard scores on CELF 4 Receptive and Expressive Language Index and British Picture Vocabulary Scale $-2$.

\begin{tabular}{rccc}
\hline & Mean & SD & Range \\
\hline Age & $13 ; 4$ & 23 months & $9 ; 2-17 ; 0$ \\
CELF RLI SS & 67.1 & 13.9 & $45-99$ \\
CELF ELI SS & 63.3 & 14.9 & $45-99$ \\
BPVS SS & 76 & 15.7 & $<40-112$ \\
\hline
\end{tabular}




\section{Study Design}

Routine SLT (and indeed occupational therapy) provision within the school involves setting individual targets for each student at the beginning of each term. The core SLT is free to choose which targets (and how many) to focus on with each student and the method of therapy (although these are checked by an SLT Team Leader to ensure consistency of provision across the school). Pre-therapy performance on each target area is assessed and recorded in a database. The SLT then sets a goal for each student and each target against which post-therapy performance will be rated as "achieved" or not. At the end of each term, performance is re-assessed and a rating of "achieved" versus "not achieved" is recorded, along with the actual score. These outcomes are used to monitor therapy provision and student progress.

Our routine target-setting process was expanded for the purposes of this study during one school term to enable us to use a similar design to Mecrow et al. (2010), where each participant served as their own control. For every area of speech, language and communication which was targeted during 1:1 SLT sessions, both a target and a control measure was devised by the core SLT. The only stipulation was that all targets and their control measures had to be designed in such a way that any score could be converted to a percentage. In most cases, this was achieved by converting points achieved out of possible points to a percentage, e.g., 14/20=70\%. In a few cases, particularly those focusing more on function rather than impairment, ratings of $0-5$ were converted to a percentage $(0 \%, 20 \%$, $40 \%, 60 \%, 80 \%, 100 \%)$. We are aware that these are more unreliable, but we felt this was a desirable step in order to be able to include all areas of our 1:1 intervention in this study.

The control measures (which would not receive any intervention) had to be related to the target, but not so closely related that work on the target might be expected to generalise to improve performance on the control measure. The measures were mostly devised by the 
individual SLTs (with help from other SLTs in the project) for the specific participants they were working with. However, some measures were shared and used with several participants. Indeed, the majority of targets and controls involving receptive vocabulary used the same tests and therapy method, as we carried out a more detailed project (Wright et al., in prep), considering just this area as part of the bigger overall project reported here. For each participant, the same assessments of their performance on their target and control measures were used pre- and post-therapy. For those in the vocabulary project, all assessments were carried out "blind" by an SLT assistant employed by the school. For the remainder of the participants, their core SLT carried out the pre-therapy assessments (at the beginning of the term), but their post-therapy assessments were carried out "blind" by another SLT (at the end of the term). For the post-therapy assessments, all SLTs partnered another SLT who was unfamiliar with the details of their work. They handed all their assessment tasks to their partner, who did not know which assessments were assessing target areas and which were assessing control areas. Then, for one week, the SLTs assessed all the participants who had had intervention with their partner SLT. Thus, pre-therapy assessments were not blind and were carried out by a familiar SLT, but post-therapy assessments were blind and carried out by an SLT unfamiliar to each participant. Therefore, any bias due to familiarity or lack of blindness of the assessors is likely to be in favour of the pre-therapy testing. So, any scores which are higher at post-therapy than pre-therapy are unlikely to be due to assessor bias and are more likely to be due to practice effects, maturation, the general school curriculum, or other non-specific effects or (for the targeted areas only) the 1:1 SLT intervention provided. The control measures were crucial in order to control for the non-specific effects which can arise through carrying out testing twice. Thus, in our analyses we were interested in any differences in progress on controls (which should be due to non-specific effects) and targets (which should be due to non-specific effects plus any effect of intervention). 


\section{Targets versus controls}

Devising control measures for a wide range of target measures was challenging. For some targets, we had lists of specific items (e.g., words) which would be targeted and a list of other items which would act as controls. For other targets, the control was a related task within the same general area. For some targets where generalisation was expected (for example, previous work showed generalisation for semantic therapy with word finding, Ebbels et al., 2012), another target area was used. For examples of each of these types of targets see Table 2. For brief details of the targets, controls and therapy methods used, see the Appendices.

Table 2: examples of targets and controls of each type

\begin{tabular}{|c|c|c|}
\hline & Targets examples & Control examples \\
\hline $\begin{array}{l}\text { specific } \\
\text { items in } \\
\text { targets vs } \\
\text { controls }\end{array}$ & $\begin{array}{l}\text { targeted vocabulary items } \\
\text { targeted idioms } \\
\text { targeted irregular past tense verbs } \\
\text { targeted multisyllabic words for production }\end{array}$ & $\begin{array}{l}\text { other vocabulary items } \\
\text { other idioms } \\
\text { other irregular past tense verbs } \\
\text { other multisyllabic words }\end{array}$ \\
\hline $\begin{array}{l}\text { related areas } \\
\text { used as } \\
\text { control }\end{array}$ & $\begin{array}{l}\text { use of aux "be" } \\
\text { fricatives production } \\
\text { /I/ production } \\
\text { staff ratings of verbal social behaviours } \\
\text { staff ratings of conversation starters }\end{array}$ & $\begin{array}{l}\text { use of aux "have" } \\
\text { plosives production } \\
\text { /s/ production } \\
\text { staff ratings of non-verbal social behaviours } \\
\text { staff ratings of conversation closers }\end{array}$ \\
\hline $\begin{array}{l}\text { different } \\
\text { area as } \\
\text { control }\end{array}$ & $\begin{array}{l}\text { word finding } \\
\text { narrative structure }\end{array}$ & $\begin{array}{l}\text { idioms } \\
\text { conjunction use in narratives }\end{array}$ \\
\hline
\end{tabular}

\section{Results}

\section{Analyses by target}

In total, during the term of the study, the 72 participants worked on 120 targets between them in 1:1 intervention sessions with their core SLT. This is a mean of 1.67 targets per participant: $28(39 \%)$ participants had one 1:1 SLT target, $38(52 \%)$ had two and six (8\%) had three. The broad areas targeted and the number and percentage are shown in Table 3 . The 
majority of targets focused on receptive or expressive language. Within these, the majority of expressive language targets focused on grammar and word finding and the majority of receptive language targets focused on receptive vocabulary (see appendices for details). The mean number of hours spent on each target was 4.2 hours $(\mathrm{SD}=1.73$ hours, range: 0.5 to 10.5 hours). Sessions were usually 30 minutes long and each SLT was free to choose how much time in each session to spend on each target and over how many weeks to work on each target.

Table 3: Number and percentage of targets in each broad area

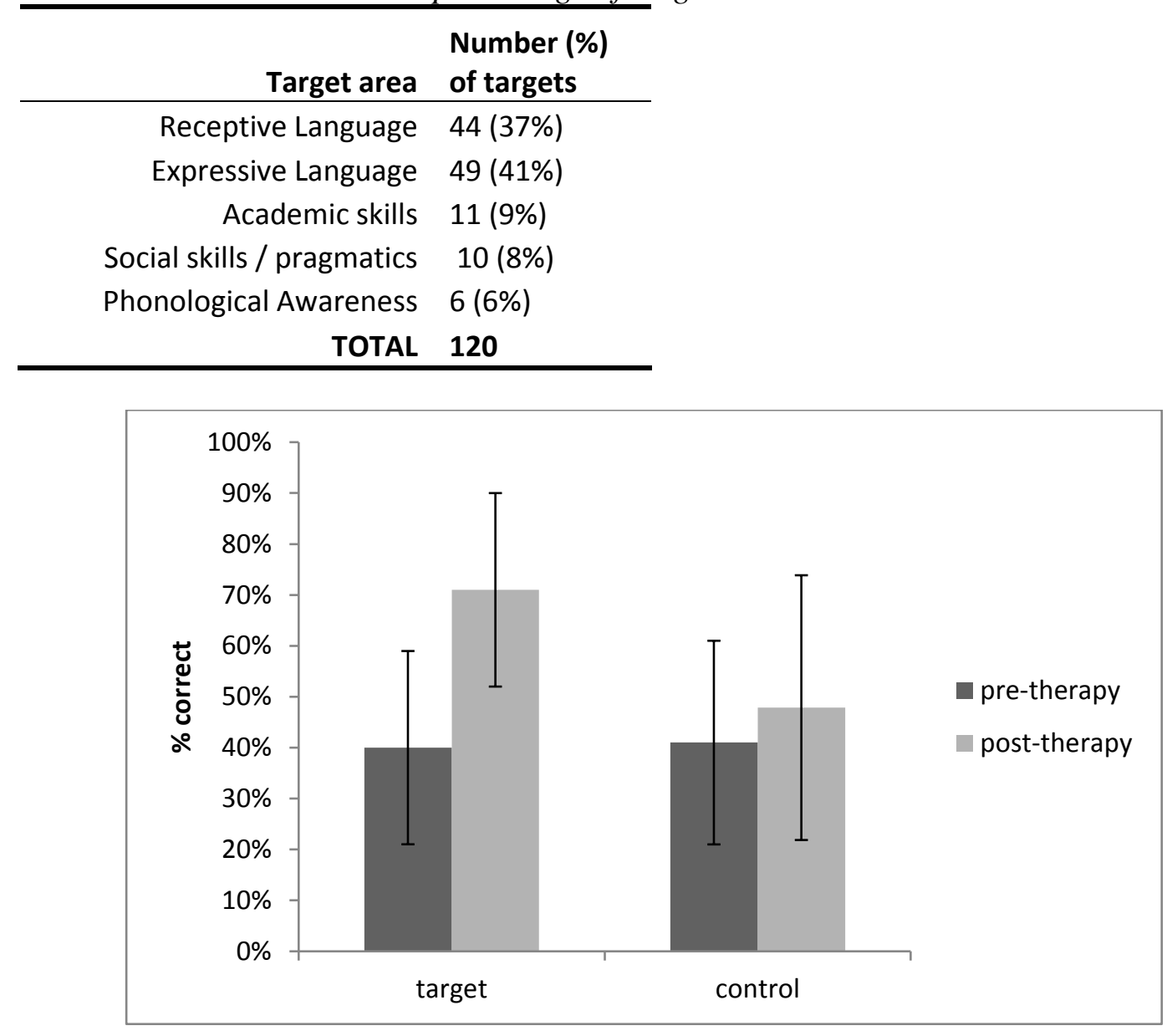

Figure 1 - mean scores on targets and controls pre- and post-therapy. Error bars show one standard deviation.

Figure 1 shows the pre- and post-therapy scores on targets and controls averaged over all the targets. This shows that pre-therapy scores on targets and controls were similar (indeed 
a paired samples $t$-test confirmed this, $t(119)=0.14, p=0.89, d=0.05)$ and that on average the participants made more progress on targets (30\%) than their controls (8\%). Figure 2 shows the change in score (post-therapy minus pre-therapy scores) for targets and controls, split by broad target area (shown in order of frequency). This shows that targets improved more than controls in all areas, although the gap was smaller for social skills/pragmatics. We analysed progress of targets and controls using change scores as the same tests were carried out with each participant pre- and post-therapy. A 2x5 ANOVA with a within-subjects factor of type (target vs. control) and a between-subjects factor target area (expressive language, receptive language, academic skills, social skills/pragmatics and phonological awareness) was carried out. This showed a significant main effect of Type, $F(1)=50.2, p<.001, \eta p^{2}=0.30$, where the change in targets was greater than controls $(d=1.06,95 \% C I: 1.01-1.09)$, no main effect of target area, $F(4)=1.9, p=.10, \eta p^{2}=0.06$ and no interaction between type and target area, $F(4)=1.7, p=.15, \eta p^{2}=0.06$. This shows that all target areas had a similar general pattern, where targets improved more than controls.

In order to establish whether progress on targets or controls was significantly different from zero, we carried out one-sample $t$-tests across all areas combined (due to the lack of interaction shown above). This showed that progress was significantly different from zero on targets, $t(119)=14.6, p<.001, d=1.33$ and controls, $t(119)=4.0, p<.001, d=0.36$. However, the effect size was much greater for the targets, as would be expected from the finding above that progress on targets was significantly greater than controls with a large and clinically significant effect size 


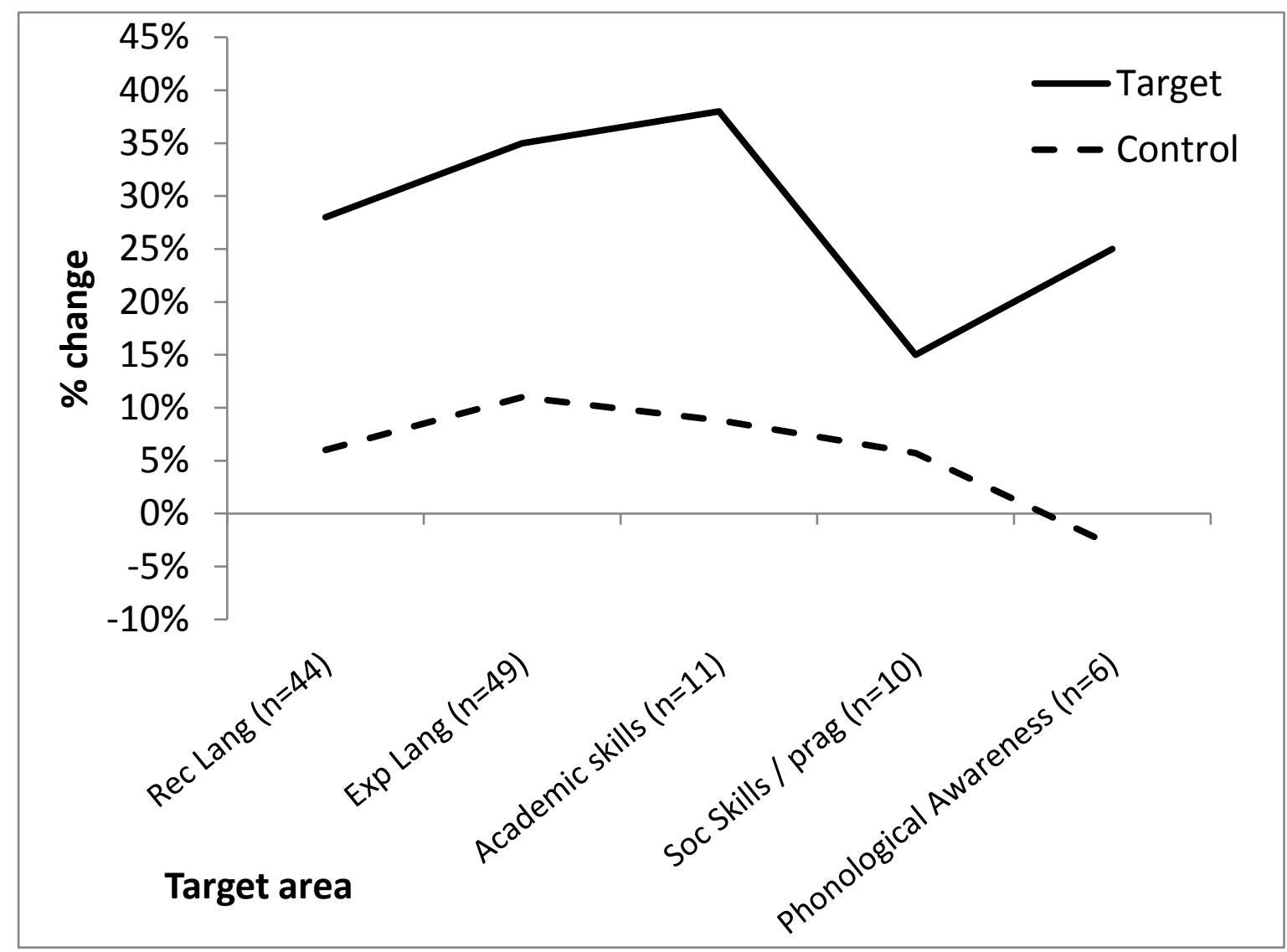

Figure 2: mean \% change with intervention on targets and controls, by target area

\section{Targets "achieved" versus "not achieved"}

As part of the target-setting system used within the school, each SLT has to set a goal for each student for each target pre-therapy. Post-therapy, each target is rated as "achieved" or "not achieved", according to whether the goal was reached or not. This judgement depends on both the amount of progress made and the level of the goal. Thus, a student could make good progress but still not reach the goal. Thus, we would expect progress on those targets rated as "achieved" to be on average higher than those "not achieved". However, we wanted to see whether the students' progress on those targets which were "not achieved" was still greater than their paired controls (i.e., did the students make significant progress on these targets even though they did not achieve their goal). 


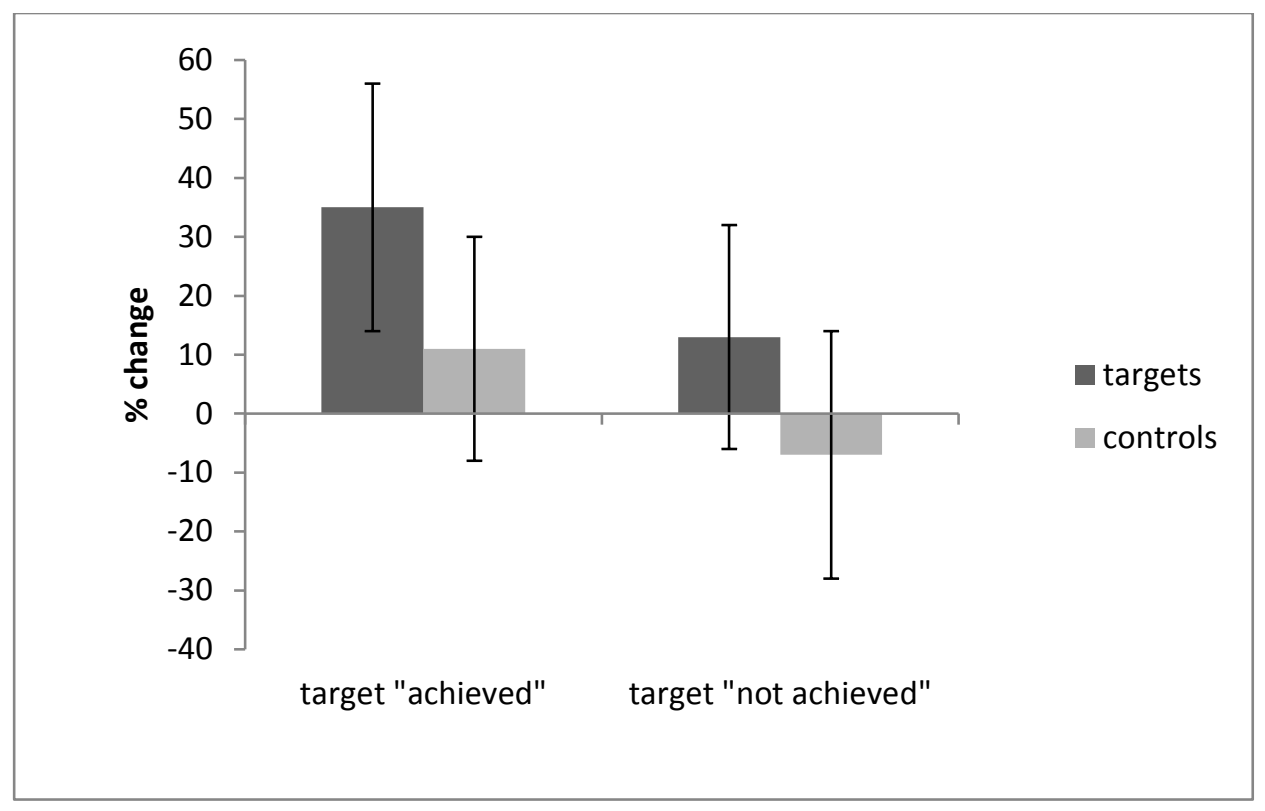

Figure 3: mean \% change with intervention on targets and controls split by whether post-therapy performance on target achieved the pre-set goal. Error bars show 1 SD.

97 targets were rated as "achieved" and 23 as "not achieved". The degree of change from pre- to post-therapy on targets versus their controls, split by whether the targets were rated post-therapy as "achieved" versus "not achieved" is shown in Figure 3. This shows that the difference between targets and their controls is similar, regardless of whether the target was rated as "achieved" or not. As expected, the degree of change is greater for those targets rated as "achieved", as greater progress is more likely to pass a threshold. A 2x5 ANOVA with a within-subjects factor of type (target vs. control) and a between-subjects factor target of achieved status ("achieved" versus "not achieved") was carried out using the change scores (post-therapy minus pre-therapy) as the dependent variable. As with previous analyses this showed a main effect of type, $F(1)=54.4, p<.001, \eta p^{2}=0.32$, where the change in targets was greater than controls. As expected, we also found a main effect of whether the target was rated as "achieved" versus "not achieved", $F(1)=29.1, p<.001, \eta p^{2}=0.20$, where greater progress was found on targets rated as "achieved". However, we found no interaction between type and achieved status, $F(1)=0.27, p=.61, \eta p^{2}=0.002$. This shows that while those 
targets rated as "achieved" showed more progress than those rated as "not achieved", their controls paralleled their progress. The gap between targets and their controls was similar in those rated as "achieved" versus "not achieved" (indeed, although not significant, the gap was numerically greater in those targets rated as "not achieved").

\section{Analyses by participant}

We were also interested in any possible effects of participant characteristics on progress with therapy. Most participants had worked on more than one target during the term. Therefore, for the following analyses, for each participant who had more than one target, we computed their mean pre-therapy score and their mean post-therapy score on both targets and controls regardless of target area.

The participant characteristics which we considered could have influenced response to therapy were: gender (male versus female), receptive language status $(<85$ versus $>85$ on the CELF-4 Receptive Language Index), ASD status (diagnosis of ASD versus no diagnosis) and Key Stage $(2,3,4)$. The results for targets versus control measures split by each characteristic are shown in Table 4. This shows all change scores for targets are higher than change scores for controls, regardless of how we split the participants. Any effect of a participant characteristic on response to intervention would be revealed by a predictor variable having a significant effect on the outcome variable. We calculated an outcome for each participant as mean progress on all targets minus mean progress on all controls (regardless of area of language targeted) to capture the difference made by intervention as opposed to general nonspecific factors which would also be expected to affect the control areas. Because the predictor factors were interrelated (particularly ASD status and gender, where most participants with ASD were boys), we carried out a multiple regression analysis with four predictors: gender, ASD status, receptive language status, school Key Stage (Key Stage 2\&3 
combined due to small numbers in Key Stage 2 vs. Key Stage 4). All predictors were entered together. The model which emerged was not significant, $F(4,67)=1.2, p=.31, R^{2}{ }_{a d j}=.01$, but receptive language status emerged as a significant predictor, $\beta=-.26, p=.04$. However, when a further regression analysis was carried out with just receptive language status entered as a predictor, the model was again not significant, $F(1,70)=3.3, p=.07, R_{a d j}^{2}=.03$.

Table 4: Mean percentage correct scores (SD) for groups of participants split on four different characteristics

\begin{tabular}{rcccccc}
\hline & $\begin{array}{c}\text { pre- } \\
\text { therapy }\end{array}$ & $\begin{array}{c}\text { Targets } \\
\text { post- } \\
\text { therapy }\end{array}$ & change & $\begin{array}{c}\text { pre- } \\
\text { therapy }\end{array}$ & $\begin{array}{c}\text { Controls } \\
\text { post- } \\
\text { therapy }\end{array}$ & change \\
\hline boys $(n=52)$ & $45(14)$ & $74(16)$ & $29(16)$ & $42(17)$ & $48(19)$ & $7(19)$ \\
girls (n=20) & $39(16)$ & $67(14)$ & $28(19)$ & $40(17)$ & $45(21)$ & $5(22)$ \\
& & & & & & \\
ASD (n=20) & $44(13)$ & $68(18)$ & $24(17)$ & $47(14)$ & $49(19)$ & $2(20)$ \\
no ASD (n=52) & $43(16)$ & $74(15)$ & $30(17)$ & $39(17)$ & $47(20)$ & $9(19)$ \\
& & & & & & \\
RELI (n=62) & $43(15)$ & $72(17)$ & $30(16)$ & $40(15)$ & $49(20)$ & $8(15)$ \\
ELI (n=10) & $49(16)$ & $73(11)$ & $24(20)$ & $45(24)$ & $38(20)$ & $-7(34)$ \\
Key Stage 2 & & & & & & \\
$(n=7)$ & $31(11)$ & $66(8)$ & $35(14)$ & $29(15)$ & $37(23)$ & $8(18)$ \\
Key Stage 3 & & & & & & \\
$(n=39)$ & $45(13)$ & $75(15)$ & $30(16)$ & $40(14)$ & $48(18)$ & $7(12)$ \\
Key Stage 4 & & & & & & \\
$(n=26)$ & $44(18)$ & $69(18)$ & $25(18)$ & $45(19)$ & $50(21)$ & $5(28)$ \\
\hline
\end{tabular}

\section{Discussion}

120 targets were delivered 1:1 by SLTs during the term in which this study took place for an average of 4.2 hours per target. These focused on a range of areas. The majority were on receptive and expressive language, with fewer targets focusing on academic and social skills (these are more often targeted in groups, with 1:1 work on these areas usually reserved for those with the most severe difficulties in these areas) and phonological awareness (a specialist literacy teacher focuses on literacy difficulties, so SLTs have less of a role in this area). Progress on targets (30\%) was significantly greater than progress on control measures 
(8\%) with a large and clinically significant effect size ( $d=1.06,95 \% \quad C I$ : 1.02-1.09), regardless of target area. This indicates that the 1:1 intervention provided by the SLTs was effective across a range of areas. Analyses of participant characteristics showed no effects on response to targeted intervention of gender, ASD status, receptive language status, or Key Stage.

Our findings of significant progress on targeted areas with therapy is similar to other studies which included secondary-aged students where the outcomes were closely related to the intervention provided (Ebbels and van der Lely, 2001, Ebbels, 2007, Ebbels et al., 2014, 2012, 2007, Hyde-Wright et al., 1993). However, our study covered a much wider range of target areas than these previous studies. We also evaluated the effectiveness of therapy as routinely provided in our setting. The only change from therapy as usual, was the addition of the control measures. Thus, our results show that 1:1 direct intervention with an SLT (including for receptive language), can be effective for these older children with severe DLD, most of whom also had receptive language impairments.

The number of hours per target (average of 4.2 hours, maximum 10.5 hours) was relatively low compared to some other studies in which participants with receptive language impairments received more than 20 hours of intervention (Boyle et al., 2009, Ebbels and van der Lely, 2001, Gillam et al., 2008, Mecrow et al., 2010, Tallal et al., 1996) with little obvious effect on receptive language in two cases (Boyle et al., 2009, Gillam et al., 2008). However, the number of hours of intervention was comparable to other studies with positive results where the participants received less than 10 hours of intervention (Ebbels, 2007, 2014, 2012, Ebbels et al., 2007, Joffe et al., 2007, Parsons et al., 2005, Throneburg et al., 2000). This shows that even a relatively small amount of targeted therapy can have a significant effect, especially where the intervention and outcome measures are closely related. 
Our analyses of progress with therapy split by whether a target was "achieved" or not, showed that targets with greater progress were more likely to be rated as "achieved". However, our results also show that much of the difference between targets which were "achieved" versus "not achieved" was probably due to non-specific effects which also affected the controls. Those targets rated as "not achieved" showed a similar gap with their controls (where performance got worse on average). Thus, it seems that factors such as having a "good" or "bad day" could be affecting the likelihood of a target being rated as "achieved" versus "not achieved". The control items control for these non-specific effects and show that on average, progress (relative to controls) was similar both on targets which were "achieved" and "not achieved". This has implications for the conclusions drawn from the results of target setting in the absence of controls. Larger versus smaller amounts of progress could be due to non-specific effects rather than those directly related to the intervention per se and are thus very difficult to interpret in the absence of any control measures. Making clinical decisions based on the amount of progress made, or when a student exceeded an arbitrary goal, is therefore likely to be unreliable in the absence of controls.

\section{Limitations and future directions}

Our study had no control group because we wanted to evaluate the effectiveness of a whole service within a particular specialist educational provision. While it might have been possible to use students of a similar age attending other provisions as a control group (particularly as many students of this age receive little or no direct intervention with an SLT), such students are likely to differ in fundamental ways from those in our study. This is due to the non-random nature of the processes involved in accessing specialist educational provisions. 
In order to provide some degree of experimental control, we used control measures for each target. Significant progress was also found on these measures (although significantly less than the targets). Due to the lack of a control group, it is not possible to say whether progress on the controls was due to maturation, practice effects, other group intervention received, collaborative teaching in the classroom or indeed generalisation of therapy. However, we were able to conclude that progress on the targeted areas was not due to such factors (as these would have affected both targets and control measures), but that the additional progress shown on the targets when compared with the controls was most likely due to the focus on these areas in 1:1 therapy sessions.

In future studies using this design, the findings would be strengthened if following the first phase of intervention, a second phase followed in which the control areas were targeted. This would mean that these areas would have a baseline period in which they received no intervention, followed by a period of intervention. Thus, progress during the baseline period could be compared with progress with intervention. If greater progress is seen with intervention during phase two on the initial control areas, this would show that these areas were not inherently more difficult to improve than the original target areas. Further testing of the original target after this term of intervention on the original control area would also enable investigation of whether the participants maintained the progress made on the original targets.

In order to investigate whether therapy generalises to other related items, it would also be desirable to include additional measures pre- and post-therapy of items/areas where generalisation is expected and compare the change on these generalisation tests with change on the control tests (where generalisation is not expected). Differences between the two would most likely be related to generalisation and not to practice effects. Indeed, in this study we deliberately avoided including items where generalisation was expected as then we would 
lose our experimental control. However, if generalisation is a particular focus of investigation a better design is to include a (waiting) control group of participants. The difference in progress on the generalisation measures for the control versus experimental group could be analysed to investigate generalisation (see for example, Ebbels et al., 2014 for generalisation to a standardised test).

This study only considered therapy outcomes in one school term. Therefore, we cannot draw conclusions from this study regarding the wider impact of the therapy. We have other studies underway which consider the longer-term effectiveness of the overall provision of the school in terms of changes on standardised tests of language, literacy and numeracy, the links between these and educational achievements and also the impact on independence and quality of life.

\section{Conclusions and implications for clinical practice}

Direct 1:1 intervention with an SLT can be effective for all areas of language for older children and adolescents with DLD, regardless of their gender, receptive language or ASD status, or age. This adds to the relatively limited evidence base regarding the effectiveness of direct SLT intervention for (older) school-aged children with DLD and for school-aged children with receptive language impairments. Children and young people such as those in our study would often be regarded as hard-to-treat. Therefore, if direct 1:1 intervention can be effective with this group, it may well also be effective with younger children with DLD. Thus, direct SLT services should be available for school-aged children with DLD, including older children and adolescents with severe, pervasive and persistent Developmental Language Disorder. 


\section{Acknowledgements}

We would like to thank our SLT assistants (Sarah Bayliss, Susan Pope and Lauren Frost) who acted as blind assessors for in this project.

\section{Declaration of interest}

BEITCHMAN, J. H., WILSON, B., BROWNLIE, E. B., WALTERS, H. \& LANCEE, W. 1996. Long-term consistency in speech/language profiles: 1. developmental and academic outcomes. Journal of the American Academy of Child and Adolescent Psychiatry, 35, 804-814.

BISHOP, D. V. M., ADAMS, C. V. \& ROSEN, S. 2006. Resistance of grammatical impairment to computerized comprehension training in children specific and nonspecific language impairments. International Journal of Language \& Communication Disorders, 41, 19-40.

BOYLE, J. M., MCCARTNEY, E., O'HARE, A. \& FORBES, J. 2009. Direct versus indirect and individual versus group modes of language therapy for children with primary language impairment: principal outcomes from a randomized controlled trial and economic evaluation. International Journal of Language \& Communication Disorders, 44, 826-846.

BRAGARD, A., SCHELSTRAETE, M. A., SNYERS, P. \& JAMES, D. G. H. 2012. Wordfinding intervention for children with specific language impairment: a multiple singlecase study. Language, speech, and hearing services in schools, 43, 222-234.

CLARK, A., O'HARE, A., WATSON, J., COHEN, W., COWIE, H., ELTON, R., NASIR, J. \& SECKL, J. 2007. Severe receptive language disorder in childhood-familial aspects and long-term outcomes: results from a Scottish study. Archives of Disease in Childhood, 92, 614-619.

CONTI-RAMSDEN, G. 2008. Heterogeneity of Specific Language Impairment (SLI): outcomes in adolescence. In: NORBURY, C. F., TOMBLIN, B. \& BISHOP, D. V. M. (eds.) Understanding Developmental Language Disorders. Hove: Psychology Press.

DOCKRELL, J. E., LINDSAY, G., LETCHFORD, B. \& MACKIE, C. 2006. Educational provision for children with specific speech and language difficulties: Perspectives of speech and language therapist managers. International Journal of Language and Communication Disorders, 41, 423-440.

EBBELS, S. \& VAN DER LELY, H. 2001. Meta-syntactic therapy using visual coding for children with severe persistent SLI. International Journal of Language \& Communication Disorders, 36, 345-350. 
EBBELS, S. H. 2007. Teaching grammar to school-aged children with Specific Language Impairment using Shape Coding. Child Language Teaching and Therapy, 23, 67-93.

EBBELS, S. H. 2014. Effectiveness of intervention for grammar in school-aged children with primary language impairments: A review of the evidence. Child Language Teaching and Therapy, 30, 7-40.

EBBELS, S. H., MARIC, N., MURPHY, A. \& TURNER, G. 2014. Improving comprehension in adolescents with severe receptive language impairments: a randomised control trial of intervention for coordinating conjunctions. International Journal of Language \& Communication Disorders, 49, 30-48.

EBBELS, S. H., NICOLL, H., CLARK, B., EACHUS, B., GALLAGHER, A. L., HORNIMAN, K., JENNINGS, M., MCEVOY, K., NIMMO, L. \& TURNER, G. 2012. Effectiveness of semantic therapy for word-finding difficulties in pupils with persistent language impairments: a randomized control trial. International Journal of Language \& Communication Disorders, 47, 35-51.

EBBELS, S. H., VAN DER LELY, H. K. J. \& DOCKRELL, J. E. 2007. Intervention for verb argument structure in children with persistent SLI: a randomized control trial. Journal of Speech Language and Hearing Research, 50, 1330-1349.

GILlAM, R. B., LOEB, D. F., HOFFMAN, L. M., BOHMAN, T., CHAMPLIN, C. A., THIBODEAU, L., WIDEN, J., BRANDEL, J. \& FRIEL-PATTI, S. 2008. The efficacy of Fast ForWord Language Intervention in school-age children with language impairment: A Randomized controlled trial. Journal of Speech Language and Hearing Research, 51, 97-119.

HYDE-WRIGHT, S. H., GORRIE, B., HAYNES, C. \& SHIPMAN, A. 1993. What's in a name? Comparative therapy for word-finding difficulties using semantic and phonological approaches. Child Language Teaching and Therapy, 9, 214-229.

JOFFE, V., CAIN, K. \& MARIC, N. 2007. Comprehension problems in children with specific language impairment: Does mental imagery training help? International Journal of Language \& Communication Disorders, 42, 648-664.

LAW, J., GARRETT, Z. \& NYE, N. 2003. Speech and Language Therapy Interventions for Children with Primary Speech and Language Delay or Disorder (Cochrane Review). Cochrane Database of Systematic Reviews, Issue 3, Art.No: CD004110. DOI: 10.1002/14651858.

LAW, J., RUSH, R., SCHOON, I. \& PARSONS, S. 2009. Modeling Developmental Language Difficulties From School Entry Into Adulthood: Literacy, Mental Health, and Employment Outcomes. Journal of Speech Language and Hearing Research, 52, 1401-1416.

MCCARTNEY, E., BOYLE, J., ELLIS, S., BANNATYNE, S. \& TURNBULL, M. 2011. Indirect language therapy for children with persistent language impairment in mainstream primary schools: outcomes from a cohort intervention. International Journal of Language \& Communication Disorders, 46, 74-82.

MECROW, C., BECKWITH, J. \& KLEE, T. 2010. An exploratory trial of the effectiveness of an enhanced consultative approach to delivering speech and language intervention in schools. International Journal of Language \& Communication Disorders, 45, 354367.

PARSONS, S., LAW, J. \& GASCOIGNE, M. 2005. Teaching receptive vocabulary to children with specific language impairment: a curriculum-based approach. Child Language Teaching and Therapy, 21, 39-59.

SEMEL, E., WIIG, E. H. \& SECORD, W. A. 2006. Clinical Evaluation of Language Fundamentals: Fourth edition: CELF 4, Harcourt Assessment. 
TALLAL, P., MILLER, S. L., BEDI, G., BYMA, G., WANG, X. Q., NAGARAJAN, S. S., SCHREINER, C., JENKINS, W. M. \& MERZENICH, M. M. 1996. Language comprehension in language-learning impaired children improved with acoustically modified speech. Science, 271, 81-84.

ThroneburG, R. N., CAlVERT, L. K., StURM, J. J., PARAMBOUKAS, A. A. \& PAUL, P. J. 2000. A comparison of service delivery models: effects on curricular vocabulary skills in the school setting. American Journal of Speech-Language Pathology, 9, 10-20.

TOMBLIN, J. B., RECORDS, N. L., BUCKWALTER, P., ZHANG, X., SMITH, E. \& O'BRIEN, M. 1997. Prevalence of Specific Language Impairment in kindergarten children. Journal of Speech Language and Hearing Research, 40, 1245-1260.

TOMBLIN, J. B., ZHANG, X., BUCKWALTER, P. \& O'BRIEN, M. 2003. The stability of primary language disorder: Four years after kindergarten diagnosis. Journal of Speech Language and Hearing Research, 46, 1283-1296.

WRIGHT, L., PRING, T. \& EBBELS, S. H. in prep. Effectiveness of vocabulary intervention for older children with Developmental Language Disorder (DLD). 
Appendices

APPENDIX A - Targets, controls and therapy methods for receptive language and vocabulary

\begin{tabular}{|c|c|c|c|}
\hline Target & Therapy method & $\begin{array}{c}\text { Number } \\
\text { of } \\
\text { targets }\end{array}$ & Control \\
\hline \multirow{3}{*}{ Receptive vocabulary } & Semantics + phonology & 27 & Other items of vocabulary \\
\hline & semantics & 3 & Other items of vocabulary \\
\hline & $\begin{array}{l}\text { Semantics + Shape Coding by Susan } \\
\text { Ebbels }^{\circledR}\end{array}$ & 1 & Other items of vocabulary \\
\hline $\begin{array}{l}\text { comprehension of words with multiple } \\
\text { meanings }\end{array}$ & Practise using context clues & 1 & expression of idioms \\
\hline Comprehension of "before" & $\begin{array}{l}\text { Shape Coding by Susan Ebbels }{ }^{\circledR} \text { plus } \\
\text { Makaton }{ }^{\circledR}\end{array}$ & 1 & Comprehension of "when" \\
\hline Understanding "where" questions & $\begin{array}{l}\text { Matching locations to "where" symbol. } \\
\text { Identifying locations in texts }\end{array}$ & 1 & Understanding "why" questions \\
\hline Comprehension of non-literal words & Practise using context clues & 1 & expression of idioms \\
\hline Idioms & Discuss literal and non-literal meanings & 5 & Non-targeted idioms \\
\hline \multirow[t]{2}{*}{ Inferencing } & Using clues in text to find meanings & 4 & Literal questions or idioms \\
\hline & TOTAL NUMBER OF TARGETS IN AREA & 44 & \\
\hline
\end{tabular}


APPENDIX B - Targets, controls and therapy methods for expressive speech, language and vocabulary

\begin{tabular}{|c|c|c|c|}
\hline Target & Therapy method & $\begin{array}{c}\text { Number } \\
\text { of } \\
\text { targets }\end{array}$ & Control \\
\hline & Nuffield Dyspraxia Programme ${ }^{\circledast}$ & 4 & Non-targeted sounds \\
\hline Speech production & $\begin{array}{l}\text { Auditory discrimination, sound in isolation } \\
\text { with cued articulation, blending sound / } \\
\text { syllables together }\end{array}$ & 1 & Non-targeted sounds \\
\hline Multisyllable word production & Nuffield Dyspraxia Programme ${ }^{\circledR}$ & 1 & Other non-targeted multisyllable words \\
\hline Multisyllable words in sentences & $\begin{array}{l}\text { Practice in gradually longer carrier } \\
\text { sentences }\end{array}$ & 1 & Other non-targeted multisyllable words \\
\hline $\begin{array}{l}\text { Giving alternate definitions of words } \\
\text { with multiple meanings }\end{array}$ & $\begin{array}{l}\text { Context and clues to meanings plus Shape } \\
\text { Coding by Susan Ebbels }{ }^{\circledR}\end{array}$ & 3 & idioms \\
\hline Word definitions & $\begin{array}{l}\text { Semantics + Shape coding by Susan } \\
\text { Ebbels }^{\circledR}\end{array}$ & 5 & Idiom explanations \\
\hline Word finding & Semantic WF therapy & 4 & Idiom explanations / expressive grammar \\
\hline Irregular past tense & $\begin{array}{l}\text { Shape Coding by Susan Ebbels }{ }^{\circledR}+\text { practice } \\
\& \text { error detection }\end{array}$ & 8 & $\begin{array}{l}\text { Other non-targeted irregular past tense verbs / irregular plurals } \\
\text { / idiom expression }\end{array}$ \\
\hline Present tense 3s & $\begin{array}{l}\text { Shape Coding by Susan Ebbels }{ }^{\circledR}+\text { practice } \\
\& \text { error detection }\end{array}$ & 2 & Use of auxiliaries \\
\hline Irregular plurals & practice \& error detection & 2 & Other non-targeted irregular plurals / irregular past tense \\
\hline Regular past tense & Shape Coding by Susan Ebbels ${ }^{\oplus}$ & 1 & Use of auxiliaries \\
\hline $\begin{array}{l}\text { Past and present tense in spontaneous } \\
\text { speech }\end{array}$ & Shape Coding by Susan Ebbels ${ }^{\circledR}$ & 1 & Variety of conjunctions used in spontaneous speech \\
\hline \multirow{2}{*}{ Forming questions } & Language Choices & 1 & Use of auxiliaries \\
\hline & Shape Coding by Susan Ebbels ${ }^{\oplus}$ & 1 & irregular past tense \\
\hline Subj-verb agreement with "be"/"have" & Shape Coding by Susan Ebbels ${ }^{\circledR}$ & 3 & Subj-verb agreement with "have"/"be" \\
\hline SVO sentences & Shape Coding by Susan Ebbels ${ }^{\circledR}$ & 1 & Use of aux is/are \\
\hline
\end{tabular}


suffixes

Use of conjunctions

Range of verbs in written narratives

Narrative structure

\section{Shape Coding by Susan Ebbels ${ }^{\circledR}$}

Sentence completion, cloze tasks, picture description

use scrapbook of weekend activities,

introduce different verbs, write sentences in $\mathrm{SVO}+$ re weekend

PEE (point, evidence, explanation)

framework, scaffolding, expansion of ideas
2

prefixes

Irregular plurals

1

range of verbs in oral narrative

$6 \quad$ Use of conjunctions in narratives 
APPENDIX C - Targets, controls and therapy methods for Academic Skills

\begin{tabular}{|c|c|c|c|}
\hline Target & Therapy method & $\begin{array}{c}\text { Number } \\
\text { of } \\
\text { targets }\end{array}$ & Control \\
\hline Using ACE dictionary & Practice plus links to THRASS ${ }^{\circledR}$ & 1 & Using traditional dictionary \\
\hline $\begin{array}{l}\text { Answering reading comprehension } \\
\text { questions }\end{array}$ & QUACK & $3)$ & \multirow{3}{*}{$\begin{array}{l}\text { Oral narrative re tricky social } \\
\text { situation; points awarded for } \\
\text { inclusion of key (narrative, } \\
\text { grammatical, social and emotional) } \\
\text { elements and relevance }\end{array}$} \\
\hline Plan GCSE essay & Shape Coding by Susan Ebbels ${ }^{\circledR}$ & $5)$ & \\
\hline \multirow[t]{2}{*}{ Non-literal comprehension } & $\begin{array}{l}\text { Identify non-literal phrase, use clues to } \\
\text { choose best option for meaning }\end{array}$ & $2)$ & \\
\hline & TOTAL NUMBER OF TARGETS IN AREA & 11 & \\
\hline
\end{tabular}


APPENDIX D - Targets, controls and therapy methods for social skills or pragmatics

\begin{tabular}{|c|c|c|c|}
\hline Target & Therapy method & $\begin{array}{l}\text { Number } \\
\text { of } \\
\text { targets }\end{array}$ & Control \\
\hline Using ipad for AAC & $\begin{array}{l}\text { Supported use of ipad in increasingly } \\
\text { functional situations, modelling, word } \\
\text { categorisation }\end{array}$ & 2 & Use of signing \\
\hline Giving reasons for opinions & $\begin{array}{l}\text { Recognising opinions and why giving } \\
\text { reasons is important, work on expansion } \\
\text { of answers }\end{array}$ & 1 & Giving details in picture descriptions \\
\hline Conversation starters & $\begin{array}{l}\text { teach strategies to get attention and tips } \\
\text { for good starters, practise with staff }\end{array}$ & 1 & Conversation closers \\
\hline Identifying consequences of actions & $\begin{array}{l}\text { Discussing past and future consequences } \\
\text { of actions }\end{array}$ & 1 & Non-literal language \\
\hline Understanding of non-literal language & $\begin{array}{l}\text { Introduction to sarcasm and clues for } \\
\text { identifying }\end{array}$ & 1 & semantics \\
\hline Verbal social behaviours & Social stories ${ }^{\mathrm{TM}}$ & 1 & Non-verbal social behaviours \\
\hline $\begin{array}{l}\text { Distinguish between "anxious" and } \\
\text { "angry" on TASIT }\end{array}$ & Social stories ${ }^{\mathrm{TM}}$ & 1 & Social inferencing on TASIT \\
\hline Active listening & Simon Says based activities & 1 & Token test \\
\hline \multirow[t]{2}{*}{ Social inferencing } & Watching videos to analyse body language & 1 & idioms \\
\hline & TOTAL NUMBER OF TARGETS IN AREA & 10 & \\
\hline
\end{tabular}


APPENDIX E - Targets, controls and therapy methods for phonological awareness

\begin{tabular}{llcl}
\hline Target & Therapy method & $\begin{array}{c}\text { Number } \\
\text { of } \\
\text { targets }\end{array}$ & Control \\
\hline $\begin{array}{l}\text { Distinguish long and short vowels from } \\
\text { each other and from consonants }\end{array}$ & THRASS $^{\circledR}$ & 3 & $\begin{array}{l}\text { Identifying symbols as element / not element } \\
\text { of the periodic table }\end{array}$ \\
$\begin{array}{l}\text { Identifying number of sounds and } \\
\text { syllables in words }\end{array}$ & $\begin{array}{l}\text { Break down words into syllables, then } \\
\text { count sounds in each syllable }\end{array}$ & 2 & Matching CVC words to rhyming pairs \\
Read short vowel VC words & THRASS ${ }^{\circledR}$ & 1 & Reading long vowel VC words \\
\hline & TOTAL NUMBER OF TARGETS IN AREA & 6 & \\
\hline
\end{tabular}

